\title{
Effect of high temperature cooking on the quality of rice porridge
}

\author{
Cunshe Chen ${ }^{1,2,3}$, Siyuan Jiang ${ }^{1,2,3}$, Mengfei $\mathrm{Li}^{1,2,3}$, You $\mathrm{Li}^{1,2,3}, \mathrm{He} \mathrm{Li}^{1,2,3}$, Fen $\mathrm{Zhao}^{1,2,3}$, \\ Zhihua Pang ${ }^{1,2,3^{*}}$, Xinqi Liu Li, $^{1,3}$ \\ (1. Beijing Engineering and Technology Research Center of Food Additives, Beijing 100048, China; \\ 2. Beijing Advanced Innovation Center for Food Nutrition and Human Health, Beijing 100048, China; \\ 3. School of Food and Health, Beijing Technology and Business University, Beijing 100048, China)
}

\begin{abstract}
In order to explore the effect of high-temperature cooking instant porridge on the taste and quality of porridge, this study explored the changes in the taste quality of rice porridge under different heating times (15 $\mathrm{min}, 20 \mathrm{~min}, 25 \mathrm{~min}$ and $30 \mathrm{~min})$ at a higher initial temperature $\left(100^{\circ} \mathrm{C}\right)$, and compared with that cooked at room temperature $\left(25^{\circ} \mathrm{C}\right)$, and explained the reasons for the change. From the perspective of migration rate in moisture content, the rice porridge with special treatment has a more rapid moisture change, which makes texture, whiteness, smell and other factors change in a shorter time and increases the taste quality. It was concluded that under special treatment condition of starting with $100^{\circ} \mathrm{C}$ water and heating for $15 \mathrm{~min}$, the kinds of rice flavor increased 2.2 times, the white of rice decreased by $10.04 \%$, hardness decreased by 3.54 times, and the elasticity decreased by $35.48 \%$ respectively. In general, cooking with higher initial temperature $\left(100^{\circ} \mathrm{C}\right)$ is more valuable than cooking from $25^{\circ} \mathrm{C}$, in terms of the texture, flavor, saving time, and stable quality during the household and industrial production of instant porridge.
\end{abstract}

Keywords: rice porridge, low frequency NMR, sensory evaluation, GC-MS, confocal laser scanning microscope DOI: $10.25165 /$ j.ijabe.20211405.6412

Citation: Chen C S, Jiang S Y, Li M F, Li Y, Li H, Zhao F, et al. Effect of high temperature cooking on the quality of rice porridge. Int J Agric \& Biol Eng, 2021; 14(5): 247-254.

\section{Introduction}

Rice is one of the most important staple foods in the world. Consumers in different regions have created a variety of rice cooking methods in daily life ${ }^{[1]}$. According to the amount of water added, cooking methods can be divided into excessive water cooking and absorption cooking. Excessive water cooking refers to cooking rice grains in a large amount of water, followed with discarding part of the boiling water and the rest is placed above the fire to be partly absorbed by the rice and partly evaporated; or water is added to the rice about twice of the rice mass and then heated until the water is absorbed by the rice $\mathrm{e}^{[2-4]}$. Unlike the treatment of rice in other countries, Chinese people usually add water about 20 times of rice weight and cook from environment temperature to make porridge. In this process, since the output power of the heating device is constant, the process can be regarded as stable heating. As the cooking progresses, the leached starch is first gelatinized and dispersed on the surface of the grains, which affects the diffusion of water in the rice grains, and affects the starch gelatinization of the core part of the whole rice, in turn the

\section{Received date: 2021-01-05 Accepted date: 2021-04-26}

Biographies: Cunshe Chen, $\mathrm{PhD}$, Professor, research interests: food processing, Email: chencs@th.btbu.edu.cn; Siyuan Jiang, Postgraduate, research interests: food processing, Email: 18317776336@163.com; Mengfei Li, Postgraduate, research interests: food processing, Email: limengfei9751@163.com; You Li, $\mathrm{PhD}$, Lecturer, research interests: plant protein development, Email: liyou@btbu.edu.cn; He Li, PhD, Associate Professor, research interests: functional food development, Email: lihe@btbu.edu.cn; Fen Zhao, PhD, Associate Professor, research interests: special medical food, Email: zhaofen@btbu.edu.cn; Xinqi Liu, PhD, Professor research interests: protein resource development and functional food, Email: liuxinqi@btbu.edu.cn.

*Corresponding author: Zhihua Pang, Professor, research interests: food properties. School of Food and Health, Beijing Technology and Business University, Beijing 100048, China. Tel: +86-18811302625, Email: pangzhihua@btbu.edu.cn. hardness and the taste of the rice ${ }^{[5]}$. The importance of water migration has led many studies. Zhu et al. ${ }^{[6]}$ studied the water migration path and structuring role of water in rice grain during soaking, Tomita et al. ${ }^{[7,8]}$ used a digital microscope to establish a low-cost visualization and quantification method for the rice soaking process, and further elaborated in comparison with NMR imaging. The gelatinization of starch in rice will cause significant changes in eating quality, temperature and time are the direct influencing factors. Li et al. ${ }^{[9]}$ found that the starch gelatinization on the surface of rice grains is the key to reducing the viscosity of cooked rice. $\mathrm{Li}$ et al. ${ }^{[10]}$ studied the starch dissolution behavior of microboiled rice and found that the reduced viscosity of cooked rice may be due to the limited starch extraction behavior, i.e., stickiness was found to increase with decreasing amylose content in the whole grain, and, in the leachate, with increasing total amount of amylopectin, the proportion of short amylopectin chains, and amylopectin molecular size. Balakrishna ${ }^{[11]}$ studied the effect of HPP (high pressure processing) on the gelatinization of whole grain rice.

In addition, before gelatinization, during the soaking process, many researchers have found that different time and temperature will cause some physical changes in the rice ${ }^{[12,13]}$. High temperature immersion can hydrolyze the rice protein into free amino acids such as $\gamma$-amino butyric acid and serine, which can improve the nutritional quality ${ }^{[13,14]}$, however high temperature soaking usually results in loss of solids and increases rice color ${ }^{[13]}$. At this stage, the research on rice is more focused on the changes of trace elements in rice ${ }^{[15]}$, the effect of processing on starch in rice $^{[16,17]}$, and changes in the smell of rice bran during storage ${ }^{[18]}$. There is less research on rice porridge. And with the rapid development of the food industry, more and more researches are focused on how to save processing time. Using boiling water to cook porridge can quickly apply heat to the rice. Compared with traditional rice porridge cooking, this method can save a lot of time 
and is suitable for commercial production. So far, there has not been a theoretical analysis about the effect of boiling water on the texture of rice porridge and the sensory quality of the finished product. This study discusses the influence of high temperature on the eating quality of rice porridge, reveals the relationship between the texture, color, smell, moisture distribution and microstructure, and provides practice ideas about theoretical guidance and guidance for the industrial production of instant rice porridge and other grain products.

\section{Materials and methods}

\subsection{Materials}

Japonica rice (Jinjian Northeast Crystal Rice, Grade 2; moisture content $13.59 \% \pm 0.01 \%$; protein content $6.2 \% \pm 0.00 \%$; carbohydrate content $78.9 \% \pm 0.00 \%$. The compositions were determined using the methods of GB 5009.3-2016, GB 5009.5-2016, GB/T 37493-2019, purchased from Yonghui supermarket (Haidian District, Beijing, China) in December, 2018 and stored in a bag at room temperature before examination. Test was conducted within two months following purchase.

\subsection{Rice porridge cooking and sample preparation}

$100^{\circ} \mathrm{C}$ constant temperature cooking: four 250 mLbeakers with $200 \mathrm{~mL}$ boiling water and $10 \mathrm{~g}$ rice were heated on digital display heating magnetic stirrer for $15 \mathrm{~min}, 20 \mathrm{~min}, 25 \mathrm{~min}, 30 \mathrm{~min}$, respectively.

Gradually raising temperature cooking: four $250 \mathrm{~mL}$ beakers with $200 \mathrm{~mL}$ of $25^{\circ} \mathrm{C}$ water and $10 \mathrm{~g}$ rice were heated on a digital display heating magnetic stirrer for $15 \mathrm{~min}, 20 \mathrm{~min}, 25 \mathrm{~min}$ and 30 min, respectively.

\subsection{Rice porridge whiteness and brightness measurement}

After cooling at room temperature for $1 \mathrm{~h}$, taking $2 \mathrm{~g}$ of cooked rice grains and draining the water, the whiteness index and brightness of rice were measured with a colorimeter CR-400 (Konica Minolta Sensor Company, Osaka, Japan). Four positions of the outer ring and four positions of the inner ring were taken for data collection, and recorded the parameters of luminosity $\left(L^{*}\right)$, red-green $\left(+a^{*} /-a^{*}\right)$ and yellow/blue $\left(+b^{*} /-b^{*}\right)$. The whiteness index $(W)$ calculation were performed using the following equation ${ }^{[19]}$ :

$$
W=100-\left[\left(100-L^{*}\right)^{2}+a^{* 2}+b^{* 2}\right]^{1 / 2}
$$

\subsection{Rice porridge Texture Profile Analysis (TPA)}

Textural analysis of cooked rice was tested by a texture analyzer (Brookfield, USA) according to cooked rice grains (after cooled at room temperature for $2 \mathrm{~h}$ ) were arrayed on the platform and tested. Textural analysis used a two-cycle compression program (TPA) and TPA parameters were as follow: strain 70\%, pre-test speed/test speed/post-test speed were $1.0 \mathrm{~mm} / \mathrm{s}, 0.5 \mathrm{~mm} / \mathrm{s}$ and $1.0 \mathrm{~mm} / \mathrm{s}$, TA11/1000 cylindrical probe. Each sample was repeated 10 times.

2.5 Solid-phase microextraction gas chromatography-mass spectrometry (SPME/GC-MS) for rice porridge profiling

The 7890A-7000B gas-mass spectrometer equipped with EI ion source and NIST08 database (Agilent, U.S) was used to analyze the rice flavor volatiles. An extraction head $(50 / 30 \mu \mathrm{m}$ DVB/CAR/PDMS SPME fiber, Sulpelco, USA) was utilized for adsorption at $50^{\circ} \mathrm{C}$ for $40 \mathrm{~min}$ and equilibration for $20 \mathrm{~min}$. The desorption time and temperature were $4 \mathrm{~min}$ and $250^{\circ} \mathrm{C}$ respectively. For gas chromatography-mass spectrometry, a DB-WAX capillary column $(30 \mathrm{~m} \times 0.25 \mathrm{~mm} \times 0.25 \mathrm{~mm}$, Supeleo, USA) was used for chromatographic separation. High-purity helium (99.9999\%) as the carrier gas with a flow rate of $1.0 \mathrm{~mL} / \mathrm{min}$ was selected. The program was initially set to $45^{\circ} \mathrm{C}$ for $10 \mathrm{~min}$, increased to $230^{\circ} \mathrm{C}$ at a rate of $6^{\circ} \mathrm{C} / \mathrm{min}$, and then held for $6 \mathrm{~min}$. The mass selective detector worked in $70 \mathrm{eV}$ electron impact ionization mode, with a scanning range of 33 to $450 \mathrm{amu}$. The ion source temperature was $230^{\circ} \mathrm{C}$ and the interface temperature was $250^{\circ} \mathrm{C}$. The volatiles were identified by matching with the reference compound spectra in the NIST mass spectrometry library and the Wiley mass spectrometry library. The experiment was done in duplicate ${ }^{[20]}$.

\subsection{Low frequency nuclear magnetic resonance (LF-NMR) measurement}

According to the method from Cheng et al. ${ }^{[21]}$, the LF-NMR measurement was conducted using a nuclear magnetic resonance analyzer (NMI20-015V-I, Niumag Co., Ltd., Suzhou, China) with certain modifications. $2.0 \mathrm{~g}$ rice grains was taken for CPMG experiment, the parameters were set to: $21.3 \mathrm{MHz}$ resonance frequency, magnetic field strength of $0.50 \mathrm{~T}, \mathrm{RF}$ coil diameter of $15 \mathrm{~mm}, \mathrm{DRG} 1=3, \mathrm{SW}=200 \mathrm{kHz}, \mathrm{RG} 1=10.0 \mathrm{db}, \mathrm{PRG}=3, \mathrm{TW}=$ $2000 \mathrm{~ms}, \mathrm{NECH}=2500, \mathrm{TE}=0.6 \mathrm{~ms}, \mathrm{P} 1=10.00 \mu \mathrm{s}, \mathrm{P} 2=14.48 \mu \mathrm{s}$, $\mathrm{SF}=21 \mathrm{MHz}, \mathrm{RFD}=0.08 \mathrm{~ms}, \mathrm{NS}=8$.

\subsection{Confocal laser scanning microscope (CLSM)}

After a simple slice, samples were stained with $0.04 \%$ rhodamine and $0.4 \%$ FITC, and then placed in the CLSM (FV1200 Confocal/FLIM/FCS, Japan) for observation. The excitation/ emission wavelengths were 488/518 nm and 552/580 nm.

\subsection{Porridge sensory evaluation}

Sensory evaluation was required for each processed sample. The panel was composed of 10 members ( 5 males, 5 females, aged between 20 to30), the evaluation was conducted with reference to the national standard (GB/T15682-2008) with certain modifications. The sensory properties were determined from perspectives of fragrance, hardness, viscosity, whiteness and glossiness ${ }^{[22]}$. The samples were randomly provided to the group members and the subjects were asked to rinse their mouths thoroughly with purified water before each tasting. According to the corresponding importance degree, the score was divided into $0-15$, where 0 point indicated that the sensory stimulation was the worst and 15 points meant the strongest stimulation.

\subsection{Statistical analysis}

Except for TPA, sample data were represented by average values. SPSS 24 software (SPSS, USA) was used for one-tailed ANOVA test and Duncan multiple test. The relationships between the total moisture content and LF-NMR parameters were investigated using the Pearson correlation coefficient by OriginPro 8 software (Origin Lab Corporation, MA, USA).

\section{Results and Discussion}

\subsection{Porridge colorimetric analysis}

The whiteness and brightness of rice porridge has a directly effect on consumers' choice, and the impact of processing conditions on the whiteness and lustrous should be fully considered during production. The results showed that the brightness and whiteness of rice porridge were significantly different under different heating time and processing methods (Table 1). With gradual temperature increase from $25^{\circ} \mathrm{C}$, the brightness and whiteness of cooked rice in the porridge decreased. This phenomenon was the same as heating at $100^{\circ} \mathrm{C}$. The only difference was that when heating at $100^{\circ} \mathrm{C}$, the change in brightness and whiteness of rice grains was less obvious than heating at $25^{\circ} \mathrm{C}$. And when comparing the two sets of data with the same heating time of $15 \mathrm{~min}$, it was found that rice porridge heated at $100^{\circ} \mathrm{C}$ appeared more non-whiteness. When the 
conditions changed, the color gradually turned gray as the temperature increased which is consistent with Islam $^{[23]}$ research results. As the whiteness and brightness of the rice cooked decreased, the color was accompanied by a prominent yellow. Sila Bhattacharya ${ }^{[24]}$ has similar results when studying the effects of high temperature and cooking time on the color of brown rice. This change may be due to the increased water absorption rate of rice as temperature increased, which increased the dissolution of reducing sugars and amino acids and accelerated the Maillard reaction $^{[25,26]}$.

Table 1 Color parameters of rice porridge under different treatment conditions

\begin{tabular}{cccccc}
\hline $\begin{array}{c}\text { Processing } \\
\text { methods }\end{array}$ & $\begin{array}{c}\text { Time } \\
\text { /min }\end{array}$ & $L^{*}$ & $a^{*}$ & $b^{*}$ & $\mathrm{~W}$ \\
\hline & 15 & $72.07 \pm 0.09^{\mathrm{g}}$ & $-1.39 \pm 0.02^{\mathrm{f}}$ & $0.32 \pm 0.00^{\mathrm{h}}$ & $72.03 \pm 0.09^{\mathrm{g}}$ \\
$25^{\circ} \mathrm{C}$ & 20 & $64.35 \pm 0.00^{\mathrm{e}}$ & $-1.41 \pm 0.00^{\mathrm{e}}$ & $-0.36 \pm 0.04^{\mathrm{g}}$ & $64.32 \pm 0.00^{\mathrm{e}}$ \\
& 25 & $63.85 \pm 0.11^{\mathrm{d}}$ & $-1.97 \pm 0.01^{\mathrm{d}}$ & $-1.48 \pm 0.01^{\mathrm{d}}$ & $63.77 \pm 0.11^{\mathrm{d}}$ \\
& 30 & $63.16 \pm 0.00^{\mathrm{c}}$ & $-2.00 \pm 0.00^{\mathrm{c}}$ & $-1.72 \pm 0.01^{\mathrm{b}}$ & $63.07 \pm 0.00^{\mathrm{c}}$ \\
\hline & 15 & $64.86 \pm 0.00^{\mathrm{f}}$ & $-1.97 \pm 0.01^{\mathrm{d}}$ & $-0.47 \pm 0.01^{\mathrm{f}}$ & $64.80 \pm 0.00^{\mathrm{f}}$ \\
$100^{\circ} \mathrm{C}$ & 20 & $62.01 \pm 0.00^{\mathrm{b}}$ & $-2.07 \pm 0.01^{\mathrm{b}}$ & $-1.35 \pm 0.00^{\mathrm{e}}$ & $61.93 \pm 0.00^{\mathrm{b}}$ \\
& 25 & $62.11 \pm 0.01^{\mathrm{b}}$ & $-2.22 \pm 0.00^{\mathrm{a}}$ & $-1.53 \pm 0.00^{\mathrm{c}}$ & $62.01 \pm 0.01^{\mathrm{b}}$ \\
& 30 & $60.74 \pm 0.00^{\mathrm{a}}$ & $-2.22 \pm 0.00^{\mathrm{a}}$ & $-2.02 \pm 0.02^{\mathrm{a}}$ & $60.63 \pm 0.00^{\mathrm{a}}$
\end{tabular}

Note: $L^{*}$ is the lightness; $\mathrm{W}$ is the whiteness index; $+\mathrm{a}^{*} /-\mathrm{a}^{*}$ are redness/ greenness, $+b^{*} /-b^{*}$ are yellowness/blueness; Data are expressed as mean \pm standard deviation. Sample means with different lowercase letters in the same column are significantly different $(p \leq 0.05)$; the number of replications $(n), n \geq 8$.

\subsection{Flavor analysis}

Flavor is one of the most important quality indicators of rice products, which directly affects consumers' satisfaction, overall acceptance and the possibility of repeating purchases ${ }^{[27]}$. The flavor of rice products is not only related to the variety of rice ${ }^{[28]}$, cooking methods are also an important factor that cannot be ignored $^{[2]}$. More than 300 volatile compounds have been identified in various rice, including aldehydes, keto acids, esters, alcohols, hydrocarbons and heterocyclic compounds ${ }^{[27]}$.

The content distribution of flavor substances is shown in Table 2, among all kinds of substances, aldehydes contributed most to the overall flavor. Previous studies have shown that aldehyde had a fruity aroma at very low concentrations, but increasing the concentration will produce an unpleasant smell of oil oxidation. Aldehyde is mainly derived from the oxidation of oil in rice bran, which is the product of oxidative degradation of oleic acid ${ }^{[20]}$. Ketones, aldehydes, and heterocyclic compounds are the reaction products produced at the final stage of the Maillard reaction. As Figure 1 shows, there are 11 kinds of compounds detected under initial temperature of $25^{\circ} \mathrm{C}$ and 20 kinds of compounds detected when the initial temperature was $100^{\circ} \mathrm{C}$, which can stimulate the aroma of rice more than $25^{\circ} \mathrm{C}$, especially for aldehydes. The detail results are listed in Table 2. Besides, when the initial temperature was $100^{\circ} \mathrm{C}$, the rice porridge emited Alloaromadendrene, $\gamma$-muurolene and isocaryophyllene with woody aroma. In addition, Dodecane with alkane taste was also detected. It is speculated that the oil in the rice may have changed due to the rapid high temperature increase to produce oily taste, or c reaction produces by-products. This indicates that the rice structure has changed and needs to be further verified with a texture analyzer. Different from steamed rice, it is difficult to volatilize some water-soluble flavor factors due to the use of excessive water for cooking. Compared with steamed rice, the kinds and proportion of aroma molecules are less.

Table 2 Flavor of rice porridge with $25^{\circ} \mathrm{C} / 100^{\circ} \mathrm{C}$ initial cooking water

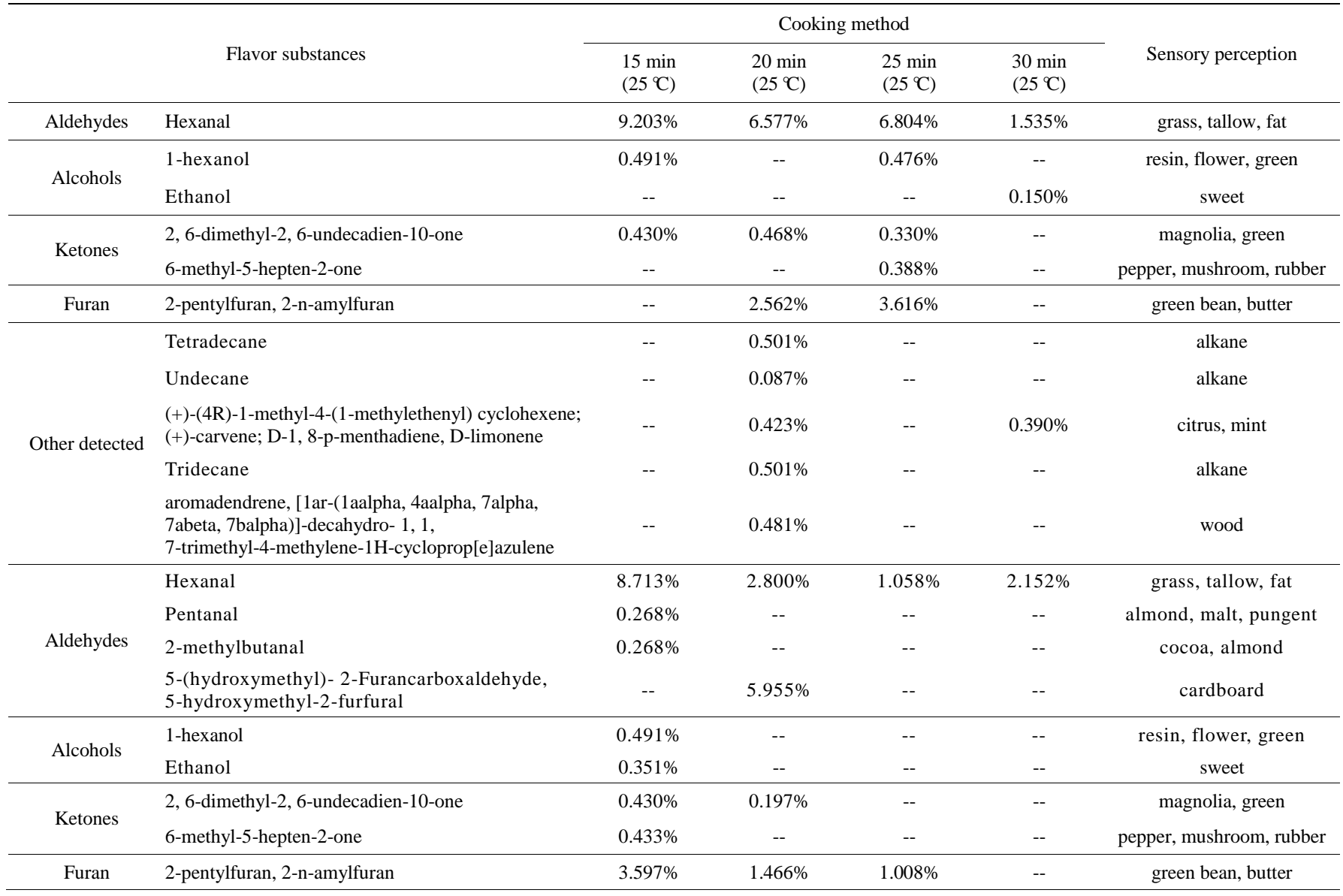




\begin{tabular}{|c|c|c|c|c|c|c|}
\hline & \multirow[b]{2}{*}{ Flavor substances } & \multicolumn{4}{|c|}{ Cooking method } & \multirow[b]{2}{*}{ Sensory perception } \\
\hline & & $\begin{array}{l}15 \min \\
\left(25^{\circ} \mathrm{C}\right)\end{array}$ & $\begin{array}{l}20 \min \\
\left(25^{\circ} \mathrm{C}\right)\end{array}$ & $\begin{array}{l}25 \mathrm{~min} \\
\left(25^{\circ} \mathrm{C}\right)\end{array}$ & $\begin{array}{l}30 \mathrm{~min} \\
\left(25^{\circ} \mathrm{C}\right)\end{array}$ & \\
\hline \multirow{11}{*}{ Other detected } & Tetradecane & $0.434 \%$ & -- & $0.537 \%$ & -- & alkane \\
\hline & Undecane & -- & -- & -- & -- & alkane \\
\hline & $\begin{array}{l}\text { (+)-(4R)-1-methyl-4-(1-methylethenyl) cyclohexene; } \\
\text { (+)-carvene; D-1, 8-p-menthadiene, D-limonene }\end{array}$ & $0.328 \%$ & $0.159 \%$ & $0.644 \%$ & $0.286 \%$ & citrus, mint \\
\hline & Tridecane & $0.434 \%$ & $0.380 \%$ & $0.537 \%$ & -- & alkane \\
\hline & $\begin{array}{l}\text { aromadendrene, [1ar-(1aalpha, 4aalpha, 7alpha, } \\
\text { 7abeta, 7balpha)]-decahydro- 1, 1, } \\
\text { 7-trimethyl-4-methylene-1H-cycloprop[e]azulene }\end{array}$ & $0.405 \%$ & $0.350 \%$ & -- & -- & wood \\
\hline & Dodecane & $1.495 \%$ & $0.637 \%$ & -- & -- & alkane \\
\hline & Alloaromadendrene & $0.405 \%$ & -- & -- & -- & wood \\
\hline & $\gamma$-muurolene & $0.405 \%$ & -- & -- & -- & herb, wood, spice \\
\hline & Isocaryophyllene & $0.405 \%$ & -- & -- & -- & wood \\
\hline & $\beta$-selinene & -- & $0.350 \%$ & -- & -- & herb \\
\hline & $\begin{array}{l}\text { methyl-4-(1-methylethenyl) cyclohexene, } \\
\text { p-mentha-1, 8-diene (mixture) }\end{array}$ & -- & -- & $0.644 \%$ & -- & lemon, orange \\
\hline
\end{tabular}

Note: The percentage in the figure refers to the ratio of the target compound odor to the total compound odor peak area; "--" means that the corresponding compound content is not detected.

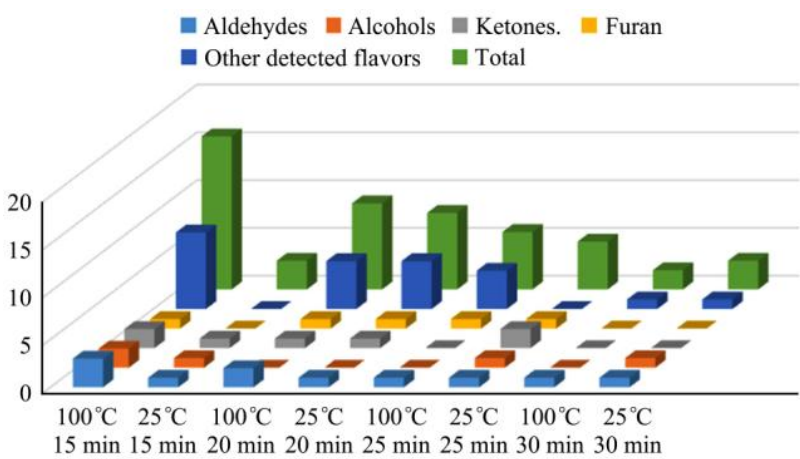

Figure 1 Amount and species of flavor compounds of cooked rice with different cooking methods

The flavor of rice porridge comes from the rice itself, oxidation during processing, and enzymatic reactions, etc. By comparing the different heating time, we can find that as the temperature increases, the flavor substances are gradually destroyed. Taking the aldehyde with obvious plant fragrance as an example, under the conditions of $25^{\circ} \mathrm{C}$ treatment and $100^{\circ} \mathrm{C}$ treatment, its percentage content gradually reduced.

When comparing the effects of different heating methods $\left(25^{\circ} \mathrm{C}\right.$ and $\left.100^{\circ} \mathrm{C}\right)$ on the flavor of rice porridge, it was found that heating for $15 \mathrm{~min}$ and $100^{\circ} \mathrm{C}$ treatment conditions, the rice porridge volatilized more kinds of aroma substances, especially hydrocarbons and heterocyclic compounds with the aroma of plants, fruit, wood-scented, oils and fats. These mixed odors can bring a unique compound fragrance to the rice porridge, which could further affect consumers' choices.

\subsection{The texture characteristics of rice porridge}

As shown in Table 3, the TPA data clearly shows that, unlike the conventional $25^{\circ} \mathrm{C}$ starting temperature cooking, $100^{\circ} \mathrm{C}$ constant temperature cooking can significantly reduce the cooking hardness, improve the elasticity, and reduce the stickiness and chewiness. Compared with conventional cooking at $25^{\circ} \mathrm{C}$, the hardness of rice porridge cooed at $100^{\circ} \mathrm{C}$ was reduced by $71.7 \%$, the elasticity increased by $35.5 \%$, the adhesiveness decreased by $32.4 \%$, and the chewiness increased by $20 \%$ at the same time for $15 \mathrm{~min}$. When comparing the same treatment conditions, as the heating time increases, the hardness of the rice grains gradually decreased, and the change was significantly slower at $100^{\circ} \mathrm{C}$ than $25^{\circ} \mathrm{C}$. The elasticity of rice cooked at $100^{\circ} \mathrm{C}$ and at the time of
$15 \mathrm{~min}, 20 \mathrm{~min}, 25 \mathrm{~min}$ and $30 \mathrm{~min}$ increased by $35.5 \%, 39.1 \%$, $44.2 \%$ and $-11.9 \%$ respectively, compared with the porridge cooked from $25^{\circ} \mathrm{C}$. Elasticity can be expressed as the initial compression that destroys the gel structure ${ }^{[8]}$. High elasticity usually manifests as the gel structure breaking into several large pieces during the first compression process, and the low elasticity is broken into many small pieces ${ }^{[29]}$. Compared with the size of the original rice grains, the rice grains absorb water and swell during the cooking process, the granules swell and break, and amylose leaches ${ }^{[30]}$. At higher temperatures, lower molecular weight amylopectin ${ }^{[31]}$ may be extracted. The leaching amount of starch is a function of temperature, and the fine structure of amylose and amylopectin are related to the texture of rice ${ }^{[32,33]}$. It can be seen from formula ${ }^{[2]}$ that when the absorbed heat is constant, the specific heat capacity of the same substance is stable, and when the starch in the rice is heavily dissolved, resulting in a decrease in the weight of a single grain of rice, the temperature inside and outside of the rice grain will change, which will further promote the rice starch gelatinization and uneven water distribution.

Table 3 Changes in the texture of rice porridge under different treatment conditions

\begin{tabular}{cccccc}
\hline $\begin{array}{c}\text { Processing } \\
\text { methods }\end{array}$ & $\begin{array}{c}\text { Time } \\
\text { /min }\end{array}$ & Hardness & Springiness & Cohesiveness & Chewiness \\
\hline \multirow{2}{*}{$25^{\circ} \mathrm{C}$} & 15 & $929.60 \pm 0.57^{\mathrm{e}}$ & $0.31 \pm 0.00^{\mathrm{a}}$ & $43.65 \pm 0.49^{\mathrm{d}}$ & $0.20 \pm 0.01^{\mathrm{e}}$ \\
& 20 & $213.00 \pm 0.00^{\mathrm{c}}$ & $0.46 \pm 0.00^{\mathrm{c}}$ & $30.00 \pm 0.00^{\mathrm{c}}$ & $0.14 \pm 0.00^{\mathrm{c}}$ \\
& 25 & $210.90 \pm 1.27^{\mathrm{b}}$ & $0.52 \pm 0.01^{\mathrm{d}}$ & $27.43 \pm 0.45^{\mathrm{b}}$ & $0.13 \pm 0.01^{\mathrm{ab}}$ \\
& 30 & $211.00 \pm 1.00^{\mathrm{b}}$ & $0.59 \pm 0.01^{\mathrm{e}}$ & $25.00 \pm 0.00^{\mathrm{a}}$ & $0.13 \pm 0.00^{\mathrm{bc}}$ \\
\hline \multirow{2}{*}{$100^{\circ} \mathrm{C}$} & 15 & $262.65 \pm 0.35^{\mathrm{d}}$ & $0.42 \pm 0.00^{\mathrm{b}}$ & $29.50 \pm 0.36^{\mathrm{c}}$ & $0.16 \pm 0.01^{\mathrm{d}}$ \\
& 20 & $187.33 \pm 0.58^{\mathrm{a}}$ & $0.64 \pm 0.01^{\mathrm{f}}$ & $27.00 \pm 0.00^{\mathrm{c}}$ & $0.13 \pm 0.01^{\mathrm{ab}}$ \\
& 25 & $186.50 \pm 0.71^{\mathrm{a}}$ & $0.75 \pm 0.00^{\mathrm{g}}$ & $27.00 \pm 0.00^{\mathrm{c}}$ & $0.12 \pm 0.01^{\mathrm{a}}$ \\
& 30 & $188.20 \pm 1.13^{\mathrm{a}}$ & $0.52 \pm 0.01^{\mathrm{d}}$ & $25.15 \pm 0.21^{\mathrm{a}}$ & $0.12 \pm 0.00^{\mathrm{ab}}$ \\
\hline
\end{tabular}

Note: Data were expressed as mean \pm standard deviation. Sample means with different lowercase letters in the same column are significantly different $(p \leq$ $0.05)$.

Chewiness is another indicator to measure the taste quality of boiled rice, which has certain correlation with hardness. As can be seen from Table 3, under a single treatment condition, as the treatment time increases, the chewiness shows a significant downward trend, which is consistent with the change in hardness. Under $25^{\circ} \mathrm{C}$ treatment conditions, from $15 \mathrm{~min}$ to $20 \mathrm{~min}$, the chewiness rate changes too fast, which is about 1.6 times the 
change value of $100^{\circ} \mathrm{C}$ under the same conditions. When heated for $15 \mathrm{~min}$ at $25^{\circ} \mathrm{C}$, due to the small amount of starch gelatinization, the rice cooked under this condition have great hardness, poor taste, continuous heating, reduced hardness, decreased cohesiveness, serious starch dissolution, and damaged rice cooked structure. When cooking for $30 \mathrm{~min}$, both the initial temperature $25^{\circ} \mathrm{C}$ and $100^{\circ} \mathrm{C}$ showed similar results with hardness, cohesiveness, chewiness tend to be stable. It is guessed that within a certain volume, the structure of rice will be destroyed and starch will dissolve seriously. With the water evaporating gradually, the dissolved starch adheres to the surface of the rice and sticks to each other, which affects the flavor and improves the taste. By comparison, heating for $15 \mathrm{~min}$ at $100^{\circ} \mathrm{C}$, the rice cooked in the rice porridge have moderate hardness, elasticity, stickiness and chewiness. Therefore, the processing method and heating time should be fully considered when processing rice.

\subsection{Moisture distribution in rice grains during cooking}

The maintenance of the shape of rice grains is related to the distribution and proportion of water molecules in the rice grains. Rice with different moisture distributions has very different tastes.

During the cooking process, the starch on the surface of the grain is first gelatinized and then dispersed in excess water. Due to the continuous penetration of water, the structure of the rice is destroyed and the adhesiveness is reduced. Especially as the cooking time increases, the water diffusion becomes more intense, and the rice grains have changed more significantly. Changes in the distribution of water cause changes in the palatability of rice porridge, which is also consistent with the analysis of TPA.

The $T_{2}$ value of the inversion spectrum is $T_{21}(0.1-2 \mathrm{~ms}), T_{22}$ (2-20 ms) and $\mathrm{T}_{23}(20-1000 \mathrm{~ms})$. The change of $\mathrm{T}_{2}$ value may be closely related to the change of microstructure ${ }^{[34]}$. The state of water molecules existing in the starch-protein gel skeleton can be reflected by the $T_{21}$ parameter. $T_{23}$ can reflect the state of free-flowing water molecules in the large voids and large grids in the microstructure, and $\mathrm{T}_{22}$ can reflect the degree of water molecule changes binding between the two. The length of time $T_{2}$ represents the ease of migration of water molecules under certain circumstances. The shorter the time, the more difficult it is to migrate water ${ }^{[35]}$, and make the rice structure more complete during cooking $^{[34]}$.

It can be seen from Table 4 that with the change of the heating time, the time of $T_{21}$ gradually becomes longer, which indicates that the protons in the starch-protein structure that are not easy to flow have exchanged with the external water molecules. As the time becomes longer, the proton exchange becomes longer. The rice grain structure is destroyed and the original grain structure cannot be maintained, showing the collapse of the grain ${ }^{[36]}$. Unlike cooking at $100^{\circ} \mathrm{C}$, in Figure 3 we can see clearly the changes in the moisture content of water in different treatments.
It can be found from Table 4 that the free-flowing water content under the conditions of $100^{\circ} \mathrm{C}$ for $15 \mathrm{~min}$ of heating is significantly higher than that under the conditions of $25^{\circ} \mathrm{C}$. The same result can also be seen from the trend after $\mathrm{T}_{23}$ in Figure 2a. Combined with Table 4 and Figure 2, we find that with the increase of heating time, $\mathrm{T}_{21}$ gradually becomes larger, indicating that the effect of external temperature has affected the exchange of moisture inside the rice grains at this moment, so that the water molecules inside the rice grains and the macromolecules migrate, the rice grains rupture. At the same time of water exchange, it causes the starch to dissolve and produce a substance with a characteristic flavor of rice. While improving the flavor, it might accelerate the Maillard reaction, deepen the color and change the hardness, which deeply affect the consumer's choice of rice porridge eating quality.

\subsection{Starch-protein framework}

According to previous reports, both protein and starch interact with water at high temperature, causing starch gelatinization and protein thermal denaturation. Due to the different distribution of protein in starch, starches that are adjacent to the protein are more likely to contact water than starches that are farther away, and gelatinize first, thereby affecting the taste quality of rice ${ }^{[37]}$. When using excess water to cook, the rice can be more easily combined with water, gelatinize faster, and make the rice softer. In order to understand the effect of initial temperature on starch and protein of whole rice grains, starch-protein framework in cooked rice were visualized for further study.

As shown in the Figure 3, under the treatment condition of $25^{\circ} \mathrm{C}$, the degree of protein denaturation gradually increases with the increase of cooking time, causing serious damage to the starch-protein backbone. During the whole process, the protein in the mesenchymal endosperm cells is first denatured when heated, and the three-dimensional network structure formed by disulfide bonds surrounds the amyloid, preventing the gelatinization of the inner $\operatorname{starch}^{[38]}$, which affects the distribution of flavor substances and reduces the quality of eating. When the heating time was extended, water entered quickly, starch gelatinization was sufficient, starch-protein skeleton was seriously damaged, and rice porridge began to become sticky. This change can be verified from the changes in TPA. When the initial temperature was $100^{\circ} \mathrm{C}$, as shown in Figure 4, the outer protein that first absorbed water was rapidly denatured, and the formed network structure made it difficult for water to enter, making the $\mathrm{T}_{21}$ value longer, the outer protein and starch were completely thermally denatured, the Maillard reaction intensified and emitted more aroma, while increasing the color of rice. This result is consistent with the whiteness and GC-MS results. As time increased, under high temperature conditions, the inner layer of starch gelatinizes, water entered quickly, and the starch-protein structure was completely destroyed, making less difference between the two treatments.

Table 4 Moisture distribution of rice grains in rice porridge under different treatment conditions

\begin{tabular}{|c|c|c|c|c|c|c|c|}
\hline Processing method & Time/min & $\mathrm{T}_{21} / \mathrm{ms}$ & $\mathrm{A}_{21} / \%$ & $\mathrm{~T}_{22} / \mathrm{ms}$ & $\mathrm{A}_{22} / \%$ & $\mathrm{~T}_{23} / \mathrm{ms}$ & $\mathrm{A}_{23} / \%$ \\
\hline \multirow{4}{*}{$25^{\circ} \mathrm{C}$} & 15 & $0.91 \pm 0.15^{\mathrm{a}}$ & $17.76 \pm 1.12^{\mathrm{c}}$ & $9.18 \pm 1.49^{\mathrm{ab}}$ & $5.71 \pm 0.01^{\mathrm{a}}$ & $54.00 \pm 0.00^{\mathrm{a}}$ & $76.52 \pm 1.13^{\mathrm{a}}$ \\
\hline & 20 & $1.35 \pm 0.18^{\mathrm{bc}}$ & $7.18 \pm 0.14^{\mathrm{ab}}$ & $9.61 \pm 1.56^{\mathrm{ab}}$ & $3.81 \pm 1.91^{\mathrm{a}}$ & $78.16 \pm 0.00^{\mathrm{c}}$ & $89.01 \pm 2.05^{\mathrm{a}}$ \\
\hline & 25 & $1.47 \pm 0.00^{\mathrm{bc}}$ & $5.25 \pm 0.31^{\mathrm{a}}$ & $12.32 \pm 0.80^{\mathrm{abc}}$ & $4.50 \pm 0.07^{\mathrm{a}}$ & $89.88 \pm 5.87^{\mathrm{de}}$ & $90.25 \pm 0.24^{\mathrm{a}}$ \\
\hline & 30 & $1.50 \pm 0.05^{\mathrm{c}}$ & $6.61 \pm 0.67^{\mathrm{ab}}$ & $11.77 \pm 0.77^{\mathrm{abc}}$ & $3.93 \pm 0.17^{\mathrm{a}}$ & $87.75 \pm 2.87^{\mathrm{de}}$ & $89.46 \pm 0.83^{\mathrm{a}}$ \\
\hline \multirow{3}{*}{$100^{\circ} \mathrm{C}$} & 15 & $1.09 \pm 0.35^{\mathrm{ab}}$ & $7.34 \pm 1.45^{\mathrm{ab}}$ & $8.71 \pm 0.28^{\mathrm{a}}$ & $3.98 \pm 0.96^{\mathrm{a}}$ & $66.51 \pm 2.17^{\mathrm{b}}$ & $88.69 \pm 0.49^{\mathrm{a}}$ \\
\hline & 25 & $1.47 \pm 0.00^{\mathrm{bc}}$ & $8.41 \pm 1.80^{\mathrm{b}}$ & $12.76 \pm 2.89^{\mathrm{bc}}$ & $4.07 \pm 0.85^{\mathrm{a}}$ & $91.90 \pm 3.00^{\mathrm{e}}$ & $87.52 \pm 2.64^{\mathrm{a}}$ \\
\hline & 30 & $1.47 \pm 0.00^{\mathrm{bc}}$ & $5.35 \pm 0.72^{\mathrm{a}}$ & $13.56 \pm 1.77^{\mathrm{c}}$ & $4.35 \pm 0.97^{\mathrm{a}}$ & $91.90 \pm 3.00^{\mathrm{e}}$ & $90.30 \pm 0.25^{\mathrm{a}}$ \\
\hline
\end{tabular}

Note: Data were expressed as mean \pm standard deviation. Sample means with different lowercase letters in the same column are significantly different $(p \leq 0.05)$. 


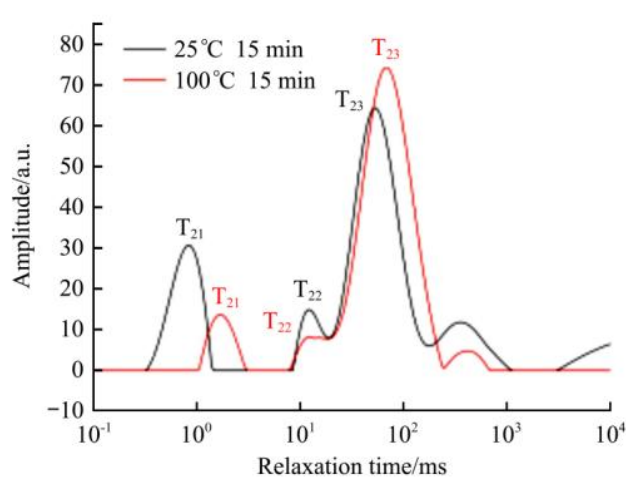

a. Initial temperature of $25^{\circ} \mathrm{C} / 100^{\circ} \mathrm{C}$ for heating $15 \mathrm{~min}$

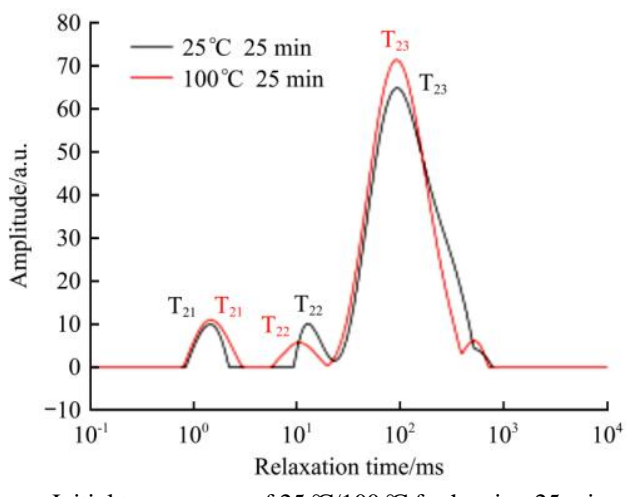

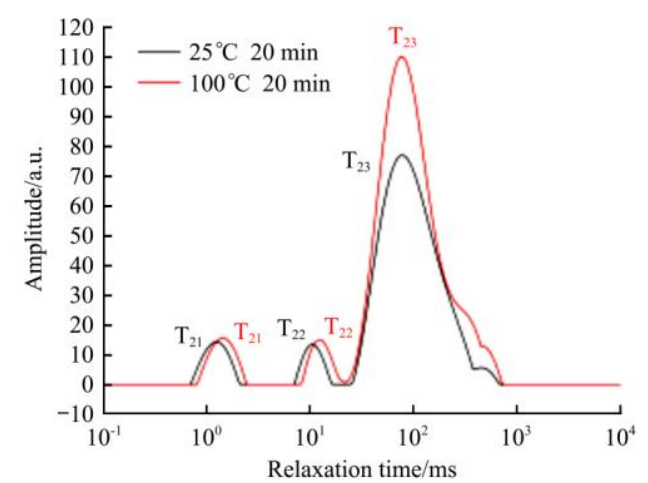

b. Initial temperature of $25^{\circ} \mathrm{C} / 100^{\circ} \mathrm{C}$ for heating $20 \mathrm{~min}$

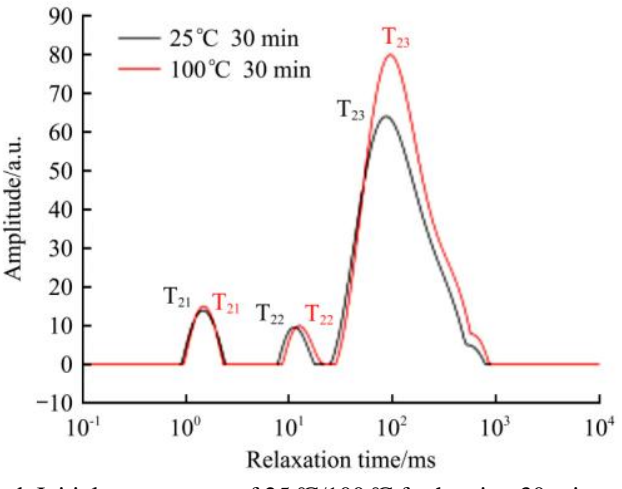

Figure 2 Distribution of water content of rice grains in rice porridge at different relaxation time under different treatment methods

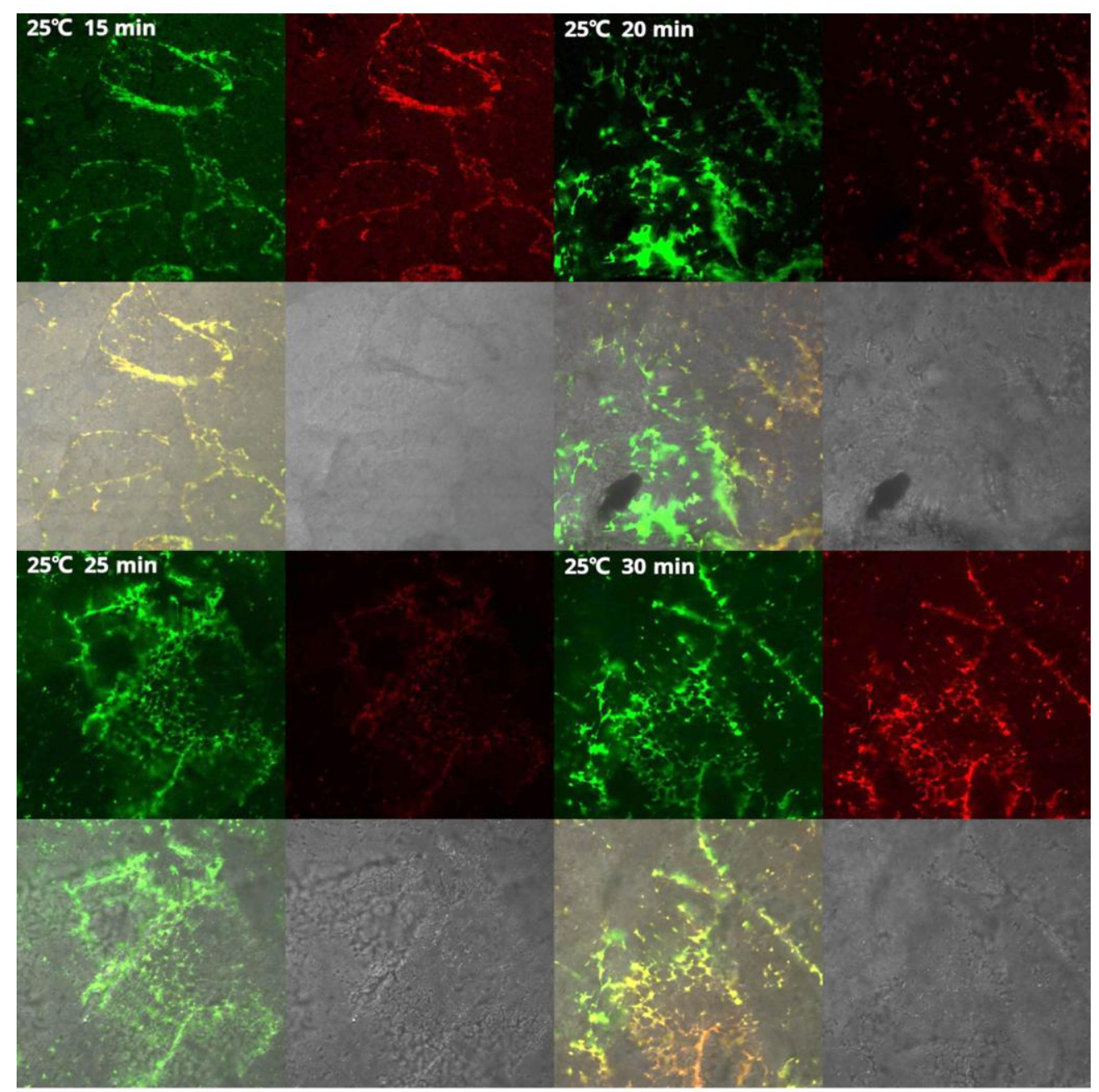

Figure 3 Starch-protein framework of cooked rice from $25^{\circ} \mathrm{C}$ by CLSM (There are four schematic diagrams under the same processing time, from top to bottom representing the structural damage of protein and starch under different wavelengths) 


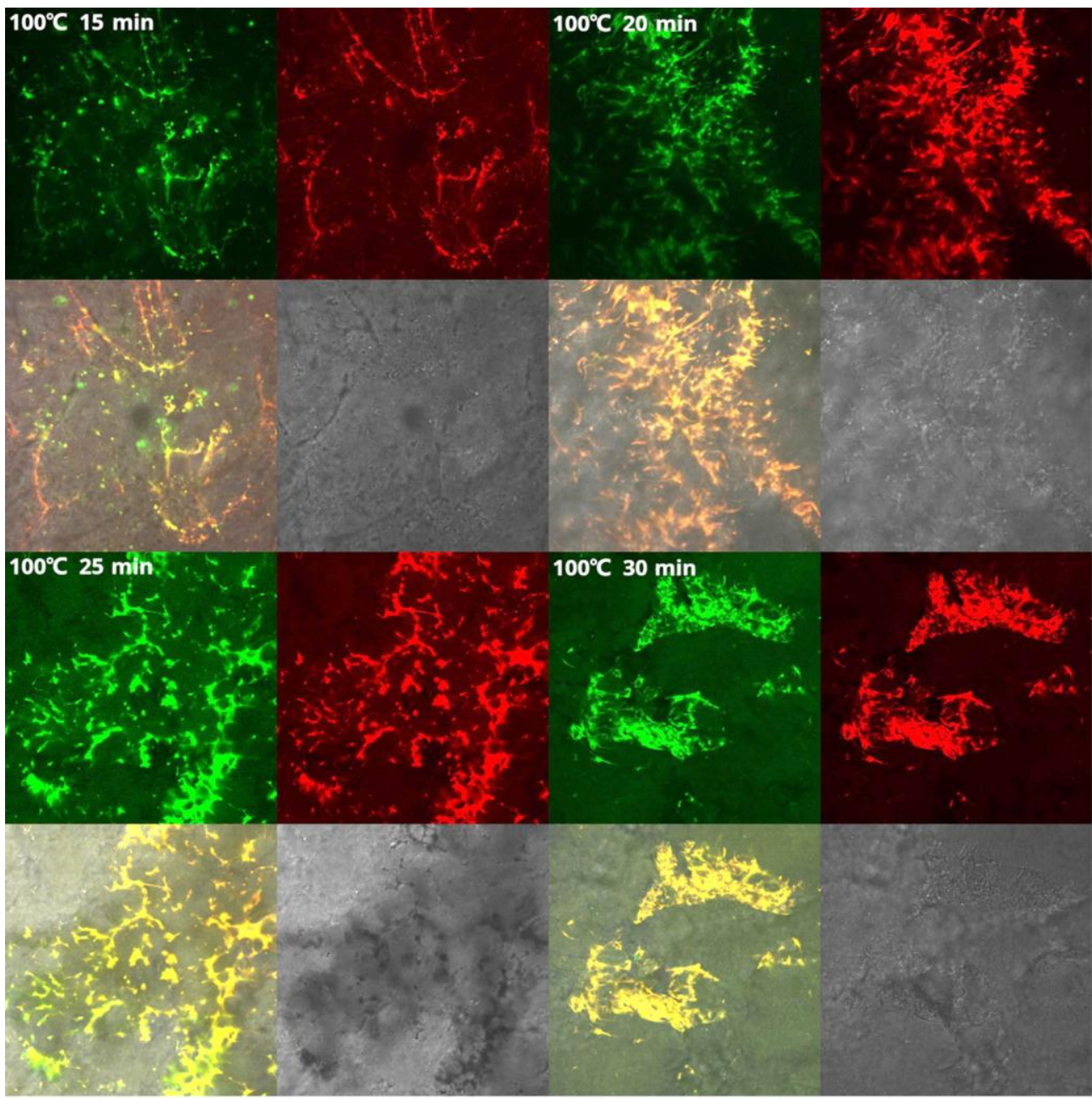

Figure 4 Starch-protein framework of cooked rice under $100^{\circ} \mathrm{C}$ by CLSM (There are four schematic diagrams under the same processing time, from top to bottom representing the structural damage of protein and starch under different wavelengths)

\subsection{Sensory evaluation}

Ten members of the sensory evaluation team conducted sensory evaluations on the two treatment methods of a total of 8 samples. The results are shown in Figure 5. The evaluation was carried out from five aspects of odor, hardness stickiness whiteness and glossiness. The evaluation results showed that porridge hardness was the highest when treated with $25^{\circ} \mathrm{C}$ initial cooking water for $15 \mathrm{~min}$, but its aroma was far inferior to that treated at $100^{\circ} \mathrm{C}$ for $15 \mathrm{~min}$. In the sensory evaluation experiment, it was found that the longer the heating time, the lower the score. In addition to the effect of texture factors on the taste, the significant reduction of aroma components is also an important factor. The

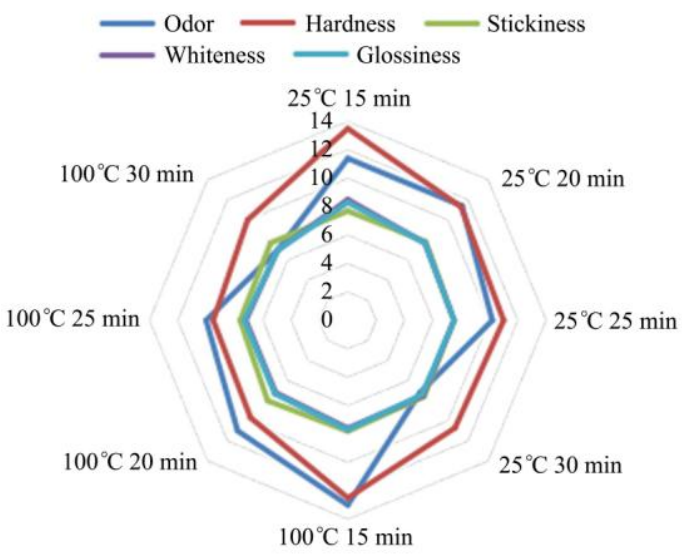

Figure 5 Sensory evaluation score of rice porridge sensory evaluation was consistent with the results obtained by GC-MS, with the best odor when treated at $100^{\circ} \mathrm{C}$ for $15 \mathrm{~min}$. The results of whiteness and glossiness showed that the higher temperature and longer heating time were, the darker the rice was. The sensory evaluation results were consistent with the colorimetric results (as shown in Table 1), indicating that Maillard reaction could have a great influence on the color change of rice products. From the sensory evaluation index, it can be seen that the results were consistent with the statistical results of the test data The total score showed that the rice porridge produced at $100^{\circ} \mathrm{C}$ for 15 min was preferred by the consumer.

\section{Conclusions}

This study clearly shows that the color, texture, moisture distribution, micro structure and flavor of cooked rice porridge were affected by cooking conditions. On this basis, sensory evaluation was used to further verify and improve the reliability of the research. By comparing rice porridge products under different treatment conditions at $25^{\circ} \mathrm{C}$ and $100^{\circ} \mathrm{C}$, it was found that heating at $100^{\circ} \mathrm{C}$ for $15 \mathrm{~min}$ can stimulate the release of more aroma substances, accelerate the maturation of rice grains, and profoundly change the taste of rice porridge. In addition, the results of low frequency nuclear magnetic resonance and CLSM revealed the influence of water distribution on texture, color and smell. The temperature change caused by the dissolution of starch affected the speed of water entering the rice grains, and further influenced the distribution of water in the rice grains, resulting in the destruction 
of the microstructure of the rice grains and changing the taste of the porridge. These findings indicate that cooking rice porridge at $100^{\circ} \mathrm{C}$ can effectively improve the palatability of rice porridge and effectively shorten the processing time. Further research is needed to verify whether instant rice porridge with high palatability can be produced in a relatively short time under the industrial production scale.

\section{Acknowledgements}

We acknowledge that this research was financially supported by the National Key Research and Development Program of China (Project No. 2016YFD0400401).

\section{[References]}

[1] Yu L, Turner M S, Fitzgerald M, Stokes J R, Witt T. Review of the effects of different processing technologies on cooked and convenience rice quality. Trends in Food Science \& Technology, 2017; 59: 124-138.

[2] Liu J K, Zheng L, Zhao S M, Xiong S B. Effect of cooking methods on volatile compounds of cooked rice. Journal of the Chinese Cereals \& Oils Association, 2007; 22(5): 12-15. (in Chinese)

[3] Son J S, Do V B, Kim K O, Cho M S, Suwonsichon T. Consumers' attitude towards rice cooking processes in Korea, Japan, Thailand and France. Food Quality \& Preference, 2013; 29: 65-75.

[4] Tian Y Q, Zhao J W, Xie Z J, Wang J P, Xu X M, Jin Z Y. Effect of different pressure-soaking treatments on color, texture, morphology and retrogradation properties of cooked rice. LWT-Food Science and Technology, 2014; 55(1): 368-373.

[5] Kasai M, Lewis A, Marica F, Ayabe S, Hatae K, Fyfe C A. NMR imaging investigation of rice cooking. Food Research International, 2005; 38: 403-410.

[6] Zhu L, Cheng L L, Zhang H, Wang L, Qian H, Qi X, et al. Research on migration path and structuring role of water in rice grain during soaking. Food Hydrocolloids, 2019; 92: 41-50.

[7] Tomita H, Fukuoka M, Takemori T, Sakai N. Development of the visualization and quantification method of the rice soaking process by using the digital microscope-ScienceDirect. Journal of Food Engineering, 2019; 243: 33-38.

[8] Hu Z Q, Shao Y F, Lu L, Fang C Y, Hu X Q, Zhu Z W. Effect of germination and parboiling treatment on distribution of water molecular, physicochemical profiles and microstructure of rice. Journal of Food Measurement and Characterization, 2019; 13: 1898-1906.

[9] Li H Y, Yan S, Yang L, Xu M H, Ji J Y, Mao H J, et al. Starch gelatinization in the surface layer of rice grains is crucial in reducing the stickiness of parboiled rice. Food Chemistry, 2020; 341(2): 128-202.

[10] Li H L, Fitzgerald M A, Prakash S, Nicholson T M, Gilbert R G. The molecular structural features controlling stickiness in cooked rice, a major palatability determinant. Scientific Reports, 2017; 7: 43713. doi: 10.1038/srep43713.

[11] Balakrishna A K, Mohammed F. Enrichment of rice with natural thiamine using high-pressure processing (HPP). Journal of Food Engineering, 2020; 283: 110040 .

[12] Chakkaravarthi A, Lakshmi S, Subramanian R, Hegde V M. Kinetics of cooking unsoaked and presoaked rice. Journal of Food Engineering, 2008; 84: 181-186.

[13] Miho Y, Kazutomo H, Hiroshi O, Thi T, Horigane A. K, Mitsuru Y, et al. Effects of soaking and high-pressure treatment on the qualities of cooked rice. Journal of Applied Glycoscience, 2005; 52: 85-93.

[14] Saikusa T, Horino T, Mori Y. Distribution of free amino acids in the rice kernel and kernel fractions and the effect of water soaking on the distribution. Journal of Agricultural \& Food Chemistry, 1994; 42: 1122-1125.

[15] Azam M M, Padmavathi S, Fiyaz R A, Waris A, Ramya K T, Neeraja C N. Effect of different cooking methods on loss of iron and zinc micronutrients in fortified and non-fortified rice. Saudi Journal of Biological Sciences,
2021; 28(5): 2886-2894

[16] Ding Y, Wang M, Shen Y, Shu X L, Wu D X, Song W J. Physiochemical properties of resistant starch and its enhancement approaches in rice. Rice Science, 2021; 28: 31-42

[17] Xu Z K, Xu Y J, Chen X J, Zhang L, Li H T, Sui Z Q, et al. Polishing conditions in rice milling differentially affect the physicochemical properties of waxy, low- and high-amylose rice starch. Journal of Cereal Science, 2021; 99: 103183.

[18] Gao C, Li Y, Pan Q F, Fan M C, Wang L, Qian H F. Analysis of the key aroma volatile compounds in rice bran during storage and processing via HS-SPME GC/MS. Journal of Cereal Science, 2021; 99: 103178. doi: 10.1016/j.jcs.2021.103178.

[19] Hunter R S. Description and measurement of white surfaces. Journal of the Optical Society of America, 1958; 48(9): 597-605.

[20] Xu D P, Hong Y, Gu Z B, Cheng L, Li Z F, Li C M. Effect of high-pressure steam on the eating quality of cooked rice. LWT-Food Science and Technology, 2019; 104: 100-108.

[21] Cheng S, Zhang T, Yao L, Wang X, Song Y, Wang H, et al. Use of low-field-NMR and MRI to characterize water mobility and distribution in pacific oyster (Crassostrea gigas) during drying process. Drying Technology, 2017; 36: 630-636.

[22] Srisawas W, Jindal V K. Sensory evaluation of cooked rice in relation to water-to-rice ratio and physicochemical properties. Journal of Texture Studies, 2007; 38: 21-41.

[23] Islam M R, Shimizu N, Kimura T. Energy requirement in parboiling and its relationship to some important quality indicators. Journal of Food Engineering, 2004; 63: 433-439.

[24] Bhattacharya S. Kinetics on colour changes in rice due to parboiling. Journal of Food Engineering, 1996; 29: 99-106.

[25] Han J A, Lim S T. Effect of presoaking on textural, thermal, and digestive properties of cooked brown rice. Cereal Chemistry, 2009; 86: 100-105.

[26] Lamberts L, Bie E D, Derycke V, Veraverbeke W S, Delcour J A. Effect of processing conditions on color change of brown and milled parboiled rice. Cereal Chemistry, 2006; 83: 80-85.

[27] Champagne, Elaine T, Rice aroma and flavor: a literature review. Cereal Chemistry, 2008; 85: 445-454.

[28] Bryant R J, Mcclung A M. Volatile profiles of aromatic and non-aromatic rice cultivars using SPME/GC-MS. Food Chemistry, 2011; 124: 501-513.

[29] Huang M, Kennedy J K, Li B, Xiao X, Xie B J. Characters of rice starch gel modified by gellan, carrageenan, and glucomannan: A texture profile analysis study. Carbohydrate Polymers, 2007; 69: 411-418.

[30] Tester R F, Morrison W R. Swelling and gelatinization of cereal starches. II. Waxy rice starches. Cereal Chemistry, 1990; 67: 558-563.

[31] Hizukuri S, Eliasson A C (Ed). Starch: analytical aspects, carbohydrates in food. Marcel Dekker, 1996; pp.347-429.

[32] Chiang P Y, Yeh A I. Effect of soaking on wet-milling of rice. Journal of Cereal Science, 2002; 35: 85-94.

[33] Ong M H, Blanshard J M V. Texture determinants in cooked, parboiled rice. I: Rice starch amylose and the fine structure of amylopectin. Journal of Cereal Science, 1995; 21(3): 251-260.

[34] Li T, Tu C H, Rui X, Gao Y W, Li W, Wang K, et al. Study of water dynamics in the soaking, steaming, and solid-state fermentation of glutinous rice by LF-NMR: a novel monitoring approach. Journal of Agricultural and Food Chemistry, 2015; 63(12): 3261-3270.

[35] Sekiyama Y, Horigane A K, Ono H, Irie K, Maeda T, Yoshida M. T2 distribution of boiled dry spaghetti measured by MRI and its internal structure observed by fluorescence microscopy. Food Research International, 2012; 48: 374-379.

[36] Bosmans G M, Lagrain B, Deleu J L, Fierens E. Assignments of proton populations in dough and bread using NMR relaxometry of starch, gluten, and flour model systems. Journal of Agricultural and Food Chemistry, 2012; 60: 5461-5470.

[37] Ahmed J, Ramaswamy H S, Ayad A, Alli I, Alvarez P. Effect of high-pressure treatment on rheological, thermal and structural changes in Basmati rice flour slurry. Journal of Cereal Science, 2007; 46: 148-156.

[38] Martin M, Fitzgerald M A. Proteins in rice grains influence cooking properties. Journal of Cereal Science, 2002; 36: 285-294. 